Revised Version

\title{
Synthesis of a three-dimensional network sodium alginate-poly(acrylic acid)/attapulgite hydrogel with good mechanic property and reusability for efficient adsorption of $\mathrm{Cu}^{2+}$ and $\mathrm{Pb}^{2+}$
}

\author{
Xinyou Mao ${ }^{1,2} \cdot$ Lan Wang $^{1} \cdot$ Shiqing Gu${ }^{1,2} \cdot$ Yanyan Duan $^{1,2} \cdot$ Yunqing Zhu $^{3} \cdot$ Chuanyi Wang $^{1,3} \mathbb{C} \cdot$ Eric Lichtfouse $^{4}$
}

\begin{abstract}
Water pollution caused by heavy metals has dramatically impacted ecosystems in recent years. For instance, $45.4 \%$ of lakes in China are in the category of moderate to high risk of toxic metal pollution, due to excessive mining. There is, therefore, a need for efficient techniques of metal decontamination. Hydrogels are gaining interest as heavy metal adsorbents because of their easy separation, but hydrogel applications are limited due to their poor mechanical property. Here we solve this problem by introducing natural attapulgite into the sodium alginate-poly(acrylic acid) semi-interpenetrating polymer network of the hydrogel. Results show that the compressive stress of the hydrogel with $10 \%$ attapulgite, of $1.230 \mathrm{Mpa}$, was 4.1 times higher than that of pure hydrogel, of $0.299 \mathrm{MPa}$. The adsorption capacity of hydrogel with $10 \%$ attapulgite was high, of $272.8 \mathrm{mg} / \mathrm{g}$ for $\mathrm{Cu}^{2+}$ and $391.7 \mathrm{mg} / \mathrm{g}$ for $\mathrm{Pb}^{2+}$. Even after five cycles of adsorption, the hydrogel with $10 \%$ attapulgite still adsorbs $261.7 \mathrm{mg} / \mathrm{g} \mathrm{Cu}^{2+}$ and $368.1 \mathrm{mg} / \mathrm{g} \mathrm{Pb}^{2+}$. Our findings thus reveal that network-structured sodium alginate-poly(acrylic acid)/attapulgite hydrogel holds great potential as an efficient and recyclable adsorbent for heavy metal removal.
\end{abstract}

Keywords Hydrogel $\cdot$ Attapulgite $\cdot \mathrm{Pb}^{2+} \cdot \mathrm{Cu}^{2+} \cdot$ Adsorption $\cdot$ Alginate

\section{Introduction}

Lan Wang

wanglan@ms.xjb.ac.cn

* Yunqing Zhu

zhuyunqing@sust.edu.cn

Chuanyi Wang

cywang@ms.xjb.ac.cn

Eric Lichtfouse

Eric.Lichtfouse@inra.fr

1 Laboratory of Environmental Sciences and Technology, Xinjiang Technical Institute of Physics and Chemistry, Key Laboratory of Functional Materials and Devices for Special Environments, Chinese Academy of Sciences, Urumqi 830011, People's Republic of China

2 University of Chinese Academy of Sciences, Beijing 100049, People's Republic of China

3 Shaanxi University of Science and Technology, Xi' an 710021, People's Republic of China

4 Collège de France, CNRS, INRA, IRD, Europôle Méditerranéen de l'Arbois, Cerege, Aix-Marseille University, 13545 Aix en Provence, France
Water pollution caused by heavy metals has dramatically impacted our life in recent years because of their excessive release into aquatic environment (Mudhoo 2012; Kiran et al. 2016). A survey showed that $45.4 \%$ of lakes in China were in the category of moderate risk and high risk concerning toxic metals, due to excessive mining, effluent and insecticide discharge (Xu et al. 2017). When the concentration of heavy metals exceeds a certain limit, it is dangerous for human health. For example, excess of lead $\left(\mathrm{Pb}^{2+}\right)$ affects the mental health of children (Gassowska et al. 2016), and excess of copper $\left(\mathrm{Cu}^{2+}\right)$ causes many diseases such as hepatocirrhosis and hemolysis (Zhu et al. 2013). Several methods have been reported for metal removal, such as membrane separation (Kurniawan et al. 2006), solvent extraction (Wang et al. 2017) and ion-exchange (Prathap and Namasivayam 2010). Recently, adsorption has been widely applied due to its ready availability and low cost (Keng et al. 2014; Muya et al. 2016).

Hydrogel is an excellent adsorbent because it is recyclable, effi and provides easy separation (Carvalho et al. 2010; Yin et al. 2008). Natural hydrophilic polymers, 
such as sodium alginate and chitosan, are considered to be good raw materials for hydrogels, but their applications as hydrogels are limited due to their poor mechanical strength (Dragan 2014). The strength of hydrogels can be enhanced by constructing semi-interpenetrating polymer network, for example, by adding poly(acrylic acid) to sodium alginate (Wu et al. 2015), or by adding poly(vinyl alcohol) to chitosan (Wan et al. 2017). However, the mechanical strength of hydrogels decreases signifi y after swelling. Some investigations have shown that the addition of clay minerals such as montmorillonite (Kaplan and Kasgoz 2011) and attapulgite (Wang et al. 2011) can improve the mechanical strength of hydrogels and also reduces its cost. Therefore, here we aimed to synthesize a novel hydrogel adsorbent by introducing natural attapulgite into the sodium alginate-poly(acrylic acid) hydrogel. To our best knowledge, this is the first synthesis of an attapulgite-modified hydrogel for heavy metal removal.

\section{Experimental}

\section{Materials}

Natural attapulgite from Jiangsu Xinyuan Technology Corp. China was crushed to obtain particles of size 200 mesh or less (size less than $61 \mu \mathrm{m}$ ), followed by pretreatment in $1 \mathrm{~mol} / \mathrm{L}$ hydrochloric acid $(\mathrm{HCl})$ solution for 3 days. This acidifi attapulgite was washed with deionized water till neutral $\mathrm{pH}$. Other chemicals, including sodium alginate, ammonium persulfate, acrylic acid, lead chloride and N,N'-methylene-bis-acrylamide, were all purchased from Sinopharm.

\section{Method}

The hydrogel without attapulgite was synthesized by the following procedure: acrylic acid (3.60 g, neutralized with $\mathrm{NaOH}), \mathrm{N}, \mathrm{N}$ '-methylene-bis-acrylamide $(0.15 \mathrm{~g})$ and water $(45.0 \mathrm{~mL})$ were all taken in a $250-\mathrm{mL}$ beaker and stirred at $600 \mathrm{rpm}$ for half hour. Then, sodium alginate $(0.30 \mathrm{~g})$ was added into the above solution and kept stirring for another $4.0 \mathrm{~h}$. After sodium alginate was fully dissolved, ammonium persulfate $(0.50 \mathrm{~g})$ was dropped into the suspension, then stirring was stopped and the reaction temperature was raised to $45^{\circ} \mathrm{C}$ for $1.0 \mathrm{~h}$. The hydrogel was washed by immersing successively in water and ethanol for $15 \mathrm{~min}$. The hydrogel was then cut into small pieces and dried at room temperature.

The synthesis of the hydrogel with attapulgite was similar, but a specified amount of attapulgite was added to the mixed solution before the addition of ammonium persulfate.
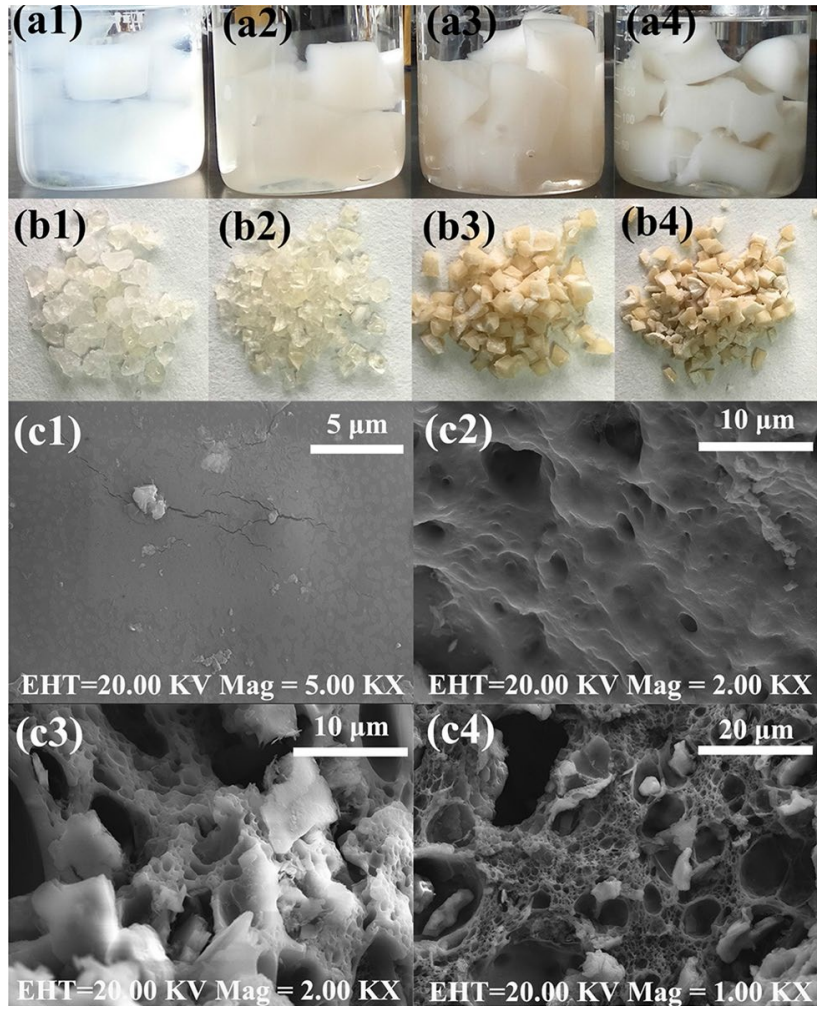

Fig. 1 a Digital photographs of hydrogels with different content attapulgite clay: $0 \%$ (a1), 10\% (a2), 20\% (a3) and 30\% (a4). b The same hydrogels after drying. c Scanning electron microscopy of the hydrogels. Note that addition of clay progressively transforms the smooth surface of the initial hydrogel (c1) into a three-dimensional network $(\mathrm{c} 2-\mathrm{c} 4)$

The digital photographs of the fi samples are shown in Fig. 1a, b.

The surface microstructures and elemental contents of hydrogels were revealed by scanning electron microscopy (Zeiss Supra55VP). Information regarding chemical bonds was obtained by Fourier transform infrared spectroscopy (Nicolet iS50). X-ray photoelectron spectroscopy (ESCALAB 250XI) was conducted at $150 \mathrm{~W}$ using $\mathrm{Al} \mathrm{K} \alpha$. The stress-strain curves were obtained using an electronic universal testing machine (MTS Criterion, Model 43). The thermostatic orbital shaker (HZQ-F160) operated at a speed of $120 \mathrm{rpm}$ at $30^{\circ} \mathrm{C}$. In the batch adsorption experiments, $25 \mathrm{mg}$ of adsorbents was used to adsorb $25 \mathrm{~mL}$ of $\mathrm{Cu}^{2+}$ or $\mathrm{Pb}^{2+}$ solutions. The concentrations of the solutions $\left(\mathrm{Cu}^{2+}\right.$ and $\mathrm{Pb}^{2+}$ ) are all set as $400 \mathrm{mg} / \mathrm{L}$. The adsorption capacities were calculated using the following equation:

$Q_{\mathrm{e}}=\frac{C_{0}-C_{\mathrm{e}} \times V}{m}$

where $Q_{\mathrm{e}}$ is the adsorption capacity ( $\mathrm{mg} / \mathrm{g}$ ). $C_{0}$ and $C_{\mathrm{e}}$ represent the initial and fi concentrations of the solution 
$(\mathrm{mg} / \mathrm{L})$, respectively, and measured by inductively coupled plasma spectrometer (ICP-OES). $V$ and $m$ are volume $(\mathrm{mL})$ of the solution and weight of the adsorbent $(\mathrm{g})$, respectively.

\section{Results and discussion}

We synthesized a novel hydrogel adsorbent by introducing natural attapulgite into the sodium alginate-poly(acrylic acid) hydrogel, in order to improve hydrogel strength. We tested adsorption of metals, desorption, $\mathrm{pH}$ effect, reusability and mechanical strength.

\section{Characterization of hydrogels}

The microscopic surfaces of hydrogels were observed by scanning electron microscopy (SEM). The pure hydrogel showed a smooth and tight surface in Fig. 1c1, whereas the hydrogel with $10 \%$ attapulgite shows a loose surface and bone-like three-dimensional structure (Fig. 1c4). This finding confirms that attapulgite promotes the formation of three dimension (3D) network porous structures in hydrogels. The structures of hydrogels with attapulgite are thus more porous compared to conventional hydrogels.
Fourier transform infrared spectroscopy (FTIR) spectra of hydrogels and attapulgite are shown in Fig. 2a. New peaks induced by addition of $10 \%$ attapulgite, at 1001 and $528 \mathrm{~cm}^{-1}$, are ascribed to the stretching vibration of $\mathrm{Si}-\mathrm{O}$ and deformation vibration of $\mathrm{Al}-\mathrm{O}-\mathrm{Si}$ bonds, respectively (Rashidzadeh et al. 2015). These new peaks prove the introduction of attapulgite in the hydrogels. After the introduction of attapulgite, the peak of hydrogel initially at $1047 \mathrm{~cm}^{-1}$, ascribed to the stretching vibration of $\mathrm{C}-\mathrm{O}-\mathrm{C}$, is shifted to $1028 \mathrm{~cm}^{-1}$, ascribed to the stretching vibration of $\mathrm{Si}-\mathrm{O}-\mathrm{C}$. This finding reveals that the chains of acrylic acid are linked to attapulgite by $\mathrm{Si}-\mathrm{O}-\mathrm{C}$ bonding at the interface between attapulgite and hydrogel, as well due to physical cross-linking. Major peaks at 3303, 1547 and $1403 \mathrm{~cm}^{-1}$ are assigned to the intermolecular hydrogen bonding of $-\mathrm{OH}$, deformation vibrations of $-\mathrm{NHR}$ and symmetric stretching vibrations of $-\mathrm{COO}^{-}$(Fan et al. 2013), respectively. These strong absorption peaks in the spectrum of the hydrogel suggest that the hydrogel possesses numerous functional groups that could chelate $\mathrm{Cu}^{2+}$ and $\mathrm{Pb}^{2+}$ ions.

The FTIR spectra of hydrogel with $10 \%$ attapulgite exhibits signifi diff ences after adsorption of $\mathrm{Cu}^{2+}$ and $\mathrm{Pb}^{2+}$ (Fig. 2b). The bands at 3303, 1547 and $1403 \mathrm{~cm}^{-1}$ shift to 3141,1547 and $1403 \mathrm{~cm}^{-1}$ after adsorption of $\mathrm{Cu}^{2+}$, (a)



(d)

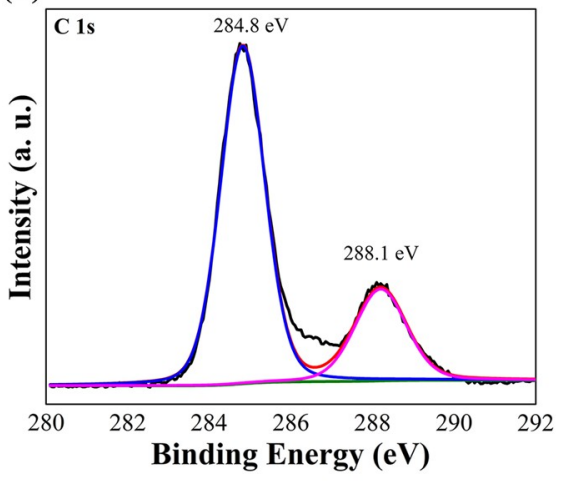

(b)

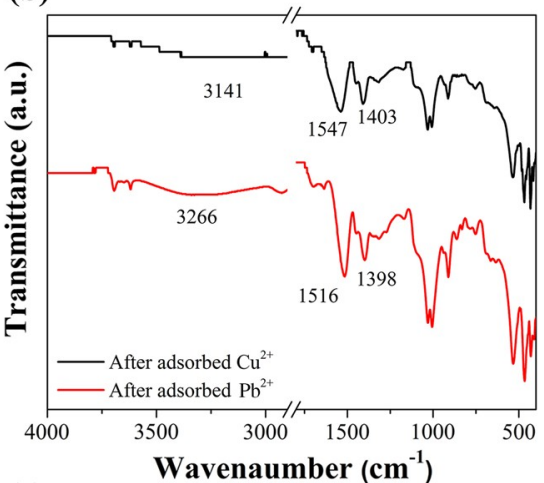

(e)

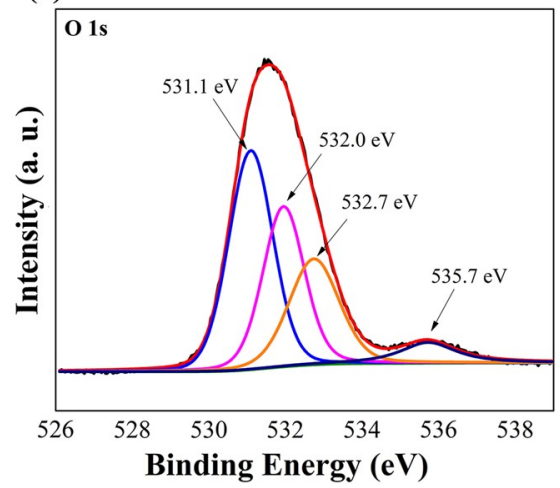

(c)

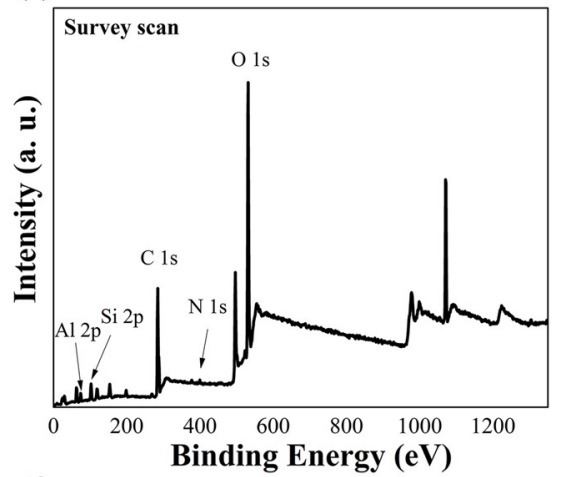

(f)

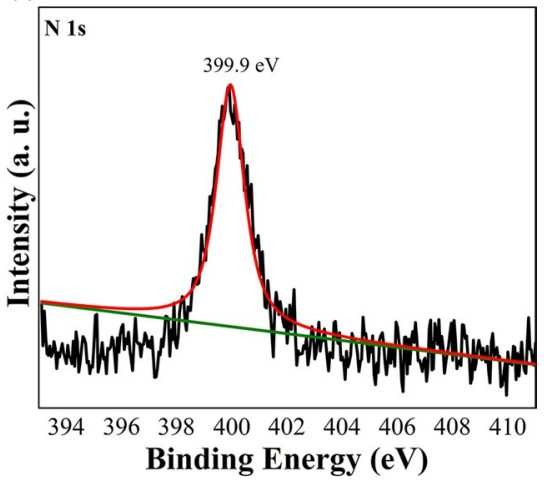

Fig. 2 a Fourier transform infrared spectroscopy of hydrogels with different content attapulgite $(0,10,20$ and $30 \%)$ and $\mathbf{b}$ hydrogels with $10 \%$ attapulgite after absorbing $\mathrm{Cu}^{2+}$ (black) and $\mathrm{Pb}^{2+}$ (red). X-ray photoelectron spectroscopy of hydrogels with $10 \%$ attapulgite: c survey scan, d C1s, e O1s, f N1s 
meanwhile shift to 3266,1516 and $1398 \mathrm{~cm}^{-1}$ after adsorption of $\mathrm{Pb}^{2+}$. The spectral shifts are caused by the strong interaction between these groups $\left(-\mathrm{OH},-\mathrm{NHR}\right.$ and $\left.-\mathrm{COO}^{-}\right)$ and $\mathrm{Cu}^{2+}$ and $\mathrm{Pb}^{2+}$ (Zhu and $\mathrm{Li} 2015$ ).

The X-ray photoelectron spectroscopy (XPS) of the hydrogel with $10 \%$ attapulgite complemented the FTIR data in Fig. 2c-f. Peaks attributed to $\mathrm{Al} 2 \mathrm{p}$ and Si $2 \mathrm{p}$ are observed in the survey scan spectrum (Fig. 2c). In the high-resolution spectrum, the broad peak of $\mathrm{C} 1 \mathrm{~s}$ before adsorption is fitted into two peaks at 284.8 and $288.1 \mathrm{eV}$, which are attributed to the $\mathrm{C}-\mathrm{H}$ bond and amide bond, respectively (Fig. 2d) (Hoffmann et al. 2005). The asymmetric shape of O1s peak before adsorption can be deconvoluted into four peaks at 531.1, $532.0,532.7$ and $535.7 \mathrm{eV}$, which were assigned to $\mathrm{O}-\mathrm{H}$, $\mathrm{C}-\mathrm{O}, \mathrm{C}=\mathrm{O}$ and carboxyl bond, respectively (Fig. 2e) (Zhang et al. 2015). N1s peak at $399.9 \mathrm{eV}$ corresponds to the $\mathrm{N}-\mathrm{H}$ bond (Fig. 2f). All results confirm the successful synthesis of the hydrogel with attapulgite.

\section{Effect of attapulgite content on hydrogel adsorption}

The metal adsorption capacity of the hydrogel was tested with increasing attapulgite clay content (Fig. 3a). Results show that the adsorption capacity only decreases from $282.6 \mathrm{mg} / \mathrm{g}$ to 249.9 for $\mathrm{Cu}^{2+}$ and from $396.1 \mathrm{mg} / \mathrm{g}$ to 362.5 for $\mathrm{Pb}^{2+}$ after introducing $30 \%$ attapulgite. This finding is in agreement with previous results showing a decrease in the adsorption capacity of hydrogels with increasing amount of attapulgite (Zhu et al. 2015). Overall, the present results show that adsorption of metal ions slightly decreases with adding attapulgite clay content.

\section{Effect of pH on hydrogel adsorption}

The adsorption of $\mathrm{Cu}^{2+}$ and $\mathrm{Pb}^{2+}$ was aff by the $\mathrm{pH}$ of the solution (Fig. 3b). Results show that the adsorption capacities of hydrogels were lower at lower $\mathrm{pH}$ values, especially lower than 2 . This is explained by the competition between protons $\left(\mathrm{H}^{+}\right)$and $\mathrm{Cu}^{2+}$ and $\mathrm{Pb}^{2+}$ ions (Bae et al. 2016). Raising the $\mathrm{pH}$ to 3.0 highly increases the adsorption capacities due to deprotonation. At $\mathrm{pH}$ of 4 and higher, adsorption capacities did not change (Fig. 3b). This is explained by the saturation of surface adsorption sites (Liu et al. 2012; Zhang et al. 2013). Overall, our results show that metal ion adsorption increases highly above $\mathrm{pH} 2$.

\section{Desorption, reusability and mechanical strength}

We studied on the effect of time and $\mathrm{HCl}$ concentration on desorption of metal ions by hydrogels with $10 \%$ attapulgite. Results show that desorption ratios for $\mathrm{Cu}^{2+}$ and $\mathrm{Pb}^{2+}$ increased with $\mathrm{HCl}$ concentration and contact time (Fig. 3a,


Fig. 3 Effects of attapulgite content and the initial $\mathrm{pH}$ of solution on adsorptions of $\mathrm{Cu}^{2+}$ and $\mathrm{Pb}^{2+}$

b). The desorption rate reached $90 \%$ using $2 \mathrm{~mol} / \mathrm{L} \mathrm{HCl}$ during $2 \mathrm{~h}$.

Moreover, we studied on the reusability of desorbed hydrogel with $10 \%$ attapulgite. The desorbed hydrogel was reused for the next adsorption process. First, concerning hydrogel with $10 \%$ attapulgite, the results show that, after five cycles, the adsorption capacities decreased from $282.9 \mathrm{mg} / \mathrm{g}$ to $261.7 \mathrm{mg} / \mathrm{g}$ for $\mathrm{Cu}^{2+}$ and decreased from $391.7 \mathrm{mg} / \mathrm{g}$ to $368.1 \mathrm{mg} / \mathrm{g}$ for $\mathrm{Pb}^{2+}$ (Fig. 4c). Due to the fragility of hydrogel alone (without clay) after one cycle, its structure was broken after three cycles (Fig. 4d). Moreover, the hydrogel with $10 \%$ attapulgite remained intact after five cycles (Fig. 4e). Overall, the finding shows that addition of clay highly improves the reusability of hydrogels.

In addition, we also studied on the effect of adding clay on the mechanical strength of the hydrogels. Results show that the pressure of the hydrogel with $10 \%$ attapulgite 

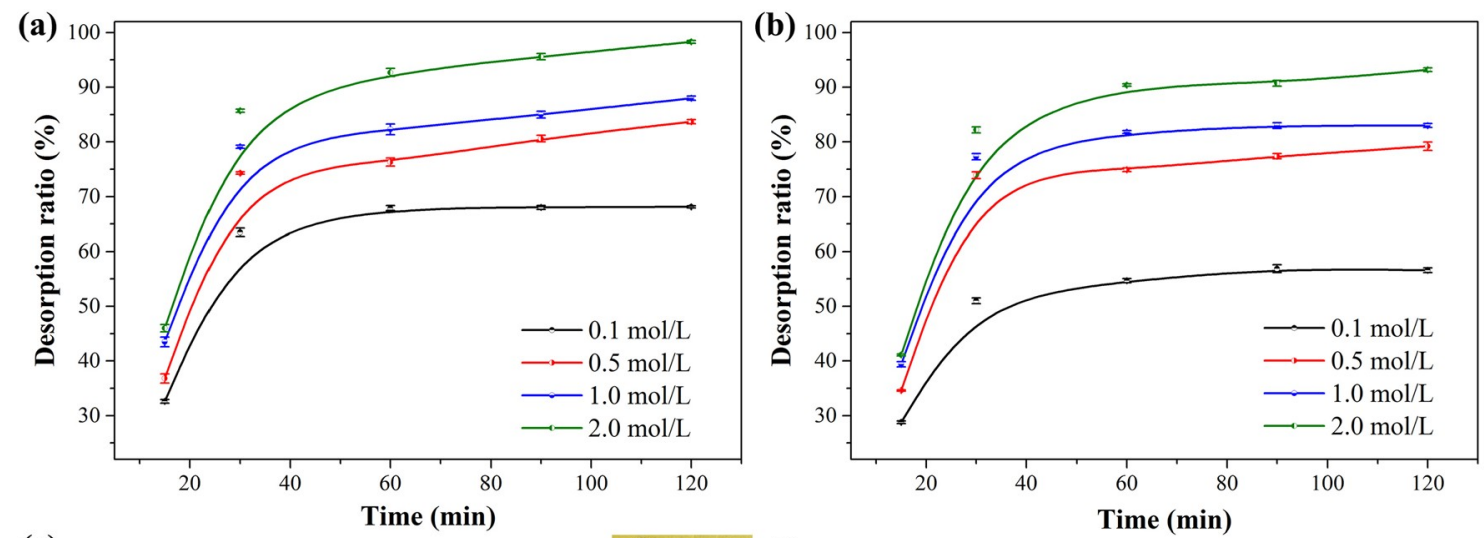

(c)

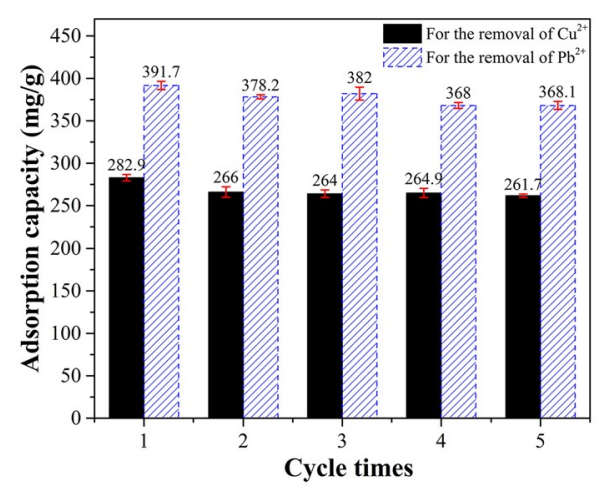

Fig. 4 Desorption ratios of hydrogels with $10 \%$ attapulgite for adsorptions of $\mathrm{Cu}^{2+}(\mathbf{a})$ and $\mathrm{Pb}^{2+}(\mathbf{b})$ ions in $\mathrm{HCl}$ solution with different concentrations. c Cycle test on the adsorption capacities of hydrogel with $10 \%$ attapulgite for $\mathrm{Cu}^{2+}$ and $\mathrm{Pb}^{2+}$ ions; digital photographs

$(1.230 \mathrm{MPa})$ is 4.1 times higher than that of hydrogel $(0.299 \mathrm{MPa})$ in Fig. 4f. These findings are in agreement with reports suggesting that the mechanical strength of a hydrogel can be effectively improved by adding clay to the hydrogel (Kong et al. 2017).

\section{Conclusion}

Our results overcome the poor mechanical properties of hydrogels used in heavy metal removal from aqueous system. The compressive stress of semi-interpenetrating polymeric 3-D network-structured hydrogel increases from 0.299 to $1.230 \mathrm{MPa}$ by addition of $10 \%$ attapulgite. Adsorption experiments show that the adsorption capacity of the hydrogel with $10 \%$ attapulgite was as high as 272.8 and $391.7 \mathrm{mg} / \mathrm{g}$ for $\mathrm{Cu}^{2+}$ and $\mathrm{Pb}^{2+}$, respectively. The hydrogel with $10 \%$ attapulgite can also retain 261.7 and $368.1 \mathrm{mg} / \mathrm{g}$ of $\mathrm{Cu}^{2+}$ and $\mathrm{Pb}^{2+}$, respectively, after five cycles.

Acknowledgements Financial support by the National Natural Science Foundation of China (Grant Nos. U1403295 and U1703129) and the

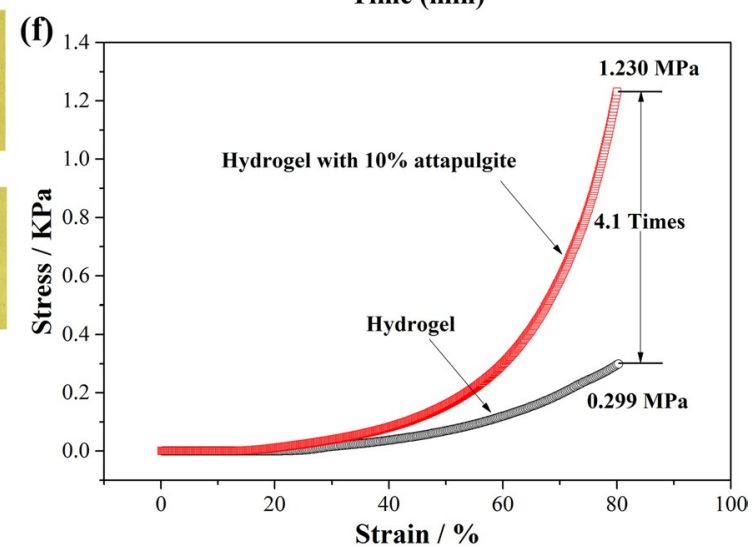

of hydrogel alone after three cycles (d) and hydrogels with $10 \%$ attapulgite after five cycles (e); f stress-strain curves for hydrogel alone and hydrogel with $10 \%$ attapulgite (water content: $80 \%$ )

CAS/SAFEA International Partnership Program for Creative Research Teams is gratefully appreciated.

\section{References}

Bae JY, Lee HJ, Choi WS (2016) Cube sugar-like sponge/polymer brush composites for portable and user-friendly heavy metal ion adsorbents. J Hazard Mater 320:133-142. https://doi. org/10.1016/j.jhazmat.2016.07.067

Carvalho HWP, Batista APL, Hammer P et al (2010) Removal of metal ions from aqueous solution by chelating polymeric hydrogel. Environ Chem Lett 8(4):343-348. https://doi.org/10.1007/s1031 1-009-0231-0

Dragan ES (2014) Design and applications of interpenetrating polymer network hydrogels. A review. Chem Eng J 243:572-590. https:// doi.org/10.1016/j.cej.2014.01.065

Fan L, Zhang JP, Wang AQ (2013) In situ generation of sodium alginate/hydroxyapatite/halloysite nanotubes nanocomposite hydrogel beads as drug-controlled release matrices. J Mater Chem B 1(45):6261-6270. https://doi.org/10.1039/C3TB20971G

Gąssowska M, Baranowskabosiacka I, Moczydłowska J et al (2016) Perinatal exposure to lead $(\mathrm{Pb})$ induces ultrastructural and molecular alterations in synapses of rat offspring. Toxicology 373:1329. https://doi.org/10.1016/j.tox.2016.10.014 
Hoffmann EA, Körtvélyesi T, Wilusz E et al (2005) Relation between $\mathrm{C} 1 \mathrm{~s}$, XPS binding energy and calculated partial charge of carbon atoms in polymers. J Mol Struct Theochem 725:5-8. https://doi. org $/ 10.1016 / j$.theochem.2005.02.021

Kaplan M, Kasgoz H (2011) Hydrogel nanocomposite sorbents for removal of basic dyes. Polym Bull 67(7):1153-1168. https://doi. org/10.1007/s00289-011-0444-9

Keng PS, Lee SL, Ha ST et al (2014) Removal of hazardous heavy metals from aqueous environment by low-cost adsorption materials. Environ Chem Lett 12(1):15-25. https://doi.org/10.1007/s1031 1-013-0427-1

Kiran MG, Pakshirajan K, Das G (2016) An overview of sulfidogenic biological reactors for the simultaneous treatment of sulfate and heavy metal rich wastewater. Chem Eng Sci 158:606-620. https ://doi.org/10.1016/j.ces.2016.11.002

Kong J, Li Z, Cao Z et al (2017) The excellent gas barrier properties and unique mechanical properties of poly(propylene carbonate)/ organo-montmorillonite nanocomposites. Polym Bull 74:50655082. https://doi.org/10.1007/s00289-017-2002-6

Kurniawan TA, Chan GYS, Lo WH et al (2006) Physico-chemical treatment techniques for wastewater laden with heavy metals. Chem Eng J 118(1-2):83-98. https://doi.org/10.1016/j.cej.2006.01.015

Liu Z, Wang H, Liu C et al (2012) Magnetic cellulose-chitosan hydrogels prepared from ionic liquids as reusable adsorbent for removal of heavy metal ions. Chem Commun 48:7350-7352. https://doi. org $/ 10.1039 / \mathrm{C} 2 \mathrm{CC} 17795 \mathrm{~A}$

Mudhoo A (2012) Removal of heavy metals by biosorption. Environ Chem Lett 10(2):109-117. https://doi.org/10.1007/s1031 1-011-0342-2

Muya FN, Sunday CE, Baker P et al (2016) Environmental remediation of heavy metal ions from aqueous solution through hydrogel adsorption: a critical review. Water Sci Technol 73:983-992. https ://doi.org/10.2166/wst.2015.567

Prathap K, Namasivayam C (2010) Adsorption of vanadate(V) on $\mathrm{Fe}(\mathrm{III}) / \mathrm{Cr}(\mathrm{III})$ hydroxide waste. Environ Chem Lett 8(4):363-371. https://doi.org/10.1007/s10311-009-0234-x

Rashidzadeh A, Olad A, Salari D (2015) The effective removal of methylene blue dye from aqueous solutions by NaAlg-gpoly(acrylic acid-co-acryl amide)/clinoptilolite hydrogel nanocomposite. Fiber Polym 16(2):354-362. https://doi.org/10.1007/ s12221-015-0354-9
Wan J, Zhu C, Hu J et al (2017) Zirconium-loaded magnetic interpenetrating network chitosan/poly(vinyl alcohol) hydrogels for phosphorus recovery from the aquatic environment. Appl Surf Sci 423:484-491. https://doi.org/10.1016/j.apsusc.2017.06.201

Wang L, Zhang JP, Wang AQ (2011) Fast removal of methylene blue from aqueous solution by adsorption onto chitosan-g-poly(acrylic acid)/attapulgite composite. Desalination 266(1):33-39. https:// doi.org/10.1016/j.desal.2010.07.065

Wang X, Wang Z, Chen $\mathrm{H}$ et al (2017) Removal of $\mathrm{Cu}(\mathrm{II})$ ions from contaminated waters using a conducting microfi ation membrane. J Hazard Mater 339:182-190. https://doi.org/10.1016/j. jhazmat.2017.06.038

Wu J, Zhou Y, Meng Y et al (2015) Synthesis and properties of sodium alginate/poly(acrylic acid) double-network superabsorbent. E-Polymers 15(4):271-278. https://doi.org/10.1515/epoly-2015-0060

$\mathrm{Xu} \mathrm{Y}, \mathrm{Wu} \mathrm{Y}$, Han J et al (2017) The current status of heavy metal in lake sediments from China: pollution and ecological risk assessment. Ecol Evol 7(14):5454-5466. https://doi.org/10.1002/ ece3.3124

Yin Y, Ji X, Dong H et al (2008) Study of the swelling dynamics with overshooting effect of hydrogels based on sodium alginateg-acrylic acid. Carbohyd Polym 71(4):682-689. https://doi. org/10.1016/j.carbpol.2007.07.012

Zhang W, Shi X, Zhang Y et al (2013) Synthesis of water-soluble magnetic graphene nanocomposites for recyclable removal of heavy metal ions. J Mater Chem A. https://doi.org/10.1039/c2ta00294a

Zhang F, Wang M, Zhou L et al (2015) Removal of Cd(II) from aqueous solution using cross-linked chitosan-zeolite composite. Desalin Water Treat 54(9):2546-2556. https://doi.org/10.1080/19443 994.2014.901190

Zhu Q, Li Z (2015) Hydrogel-supported nanosized hydrous manganese dioxide: synthesis, characterization, and adsorption behavior study for $\mathrm{Pb}^{2+}, \mathrm{Cu}^{2+}, \mathrm{Cd}^{2+}$ and $\mathrm{Ni}^{2+}$ removal from water. Chem Eng J 281:69-80. https://doi.org/10.1016/j.cej.2015.06.068

Zhu B, Yang P, Yu H et al (2013) Development of a novel water-soluble magnetic fluorescent nanoparticle for the selective detection and removal of $\mathrm{Cu}^{2+}$. Nanotechnology 24(49):495502. https://doi. org/10.1088/0957-4484/24/49/495502

Zhu Y, Zheng Y, Wang A (2015) A simple approach to fabricate granular adsorbent for adsorption of rare elements. Int J Biol Macromol 72:410-420. https://doi.org/10.1016/j.ijbiomac.2014.08.039 